\title{
Vitamin D in patients with Hashimoto's disease: a systematic review and meta-analysis
}

\author{
Josiane Marlei Muller Fernandes dos Santos ${ }^{1}$ (D), Erika Vaz Alencar², Elisa Caroline de Oliveira Martins ${ }^{2}$ \\ Cíntia Aparecida Ossoski², Aline F. Bonetti ${ }^{1 *}$ (i) \\ 'Programa de Pós-graduação em Ciências Farmacêuticas, Universidade Federal do Paraná (UFPR), Curitiba, PR, Brasil \\ ${ }^{2}$ Programa de Pós-graduação em Farmácia Clínica, Faculdades Pequeno Príncipe, Curitiba, PR, Brasil \\ *Corresponding author: alinefbonetti@gmail.com
}

\begin{abstract}
One of the most common thyroid dysfunctions is Hashimoto's disease (HD), characterized by the production of specific antibodies against thyroid gland antigens (Anti-Tg and Anti-TPO). Recent studies have suggested that vitamin D supplementation, associated with levothyroxine, may contribute to the control of this autoimmune disease. However, secondary studies on this topic, such as systematic reviews and meta-analyses, are still scarce. Thus, the present study aimed to evaluate the efficacy and safety of vitamin D in patients with HD through a systematic review with meta-analysis. Randomized clinical trials were selected on the Pubmed, Scopus, and Web of Science databases. Studies comparing groups of HD patients supplemented with vitamin D and non-supplemented HD patients were included. The following outcomes were considered: TSH, T3, $\mathrm{T} 4$, Anti-Tg, Anti-TPO, and adverse drug reactions. The risk of bias was performed according to the Cochrane recommendations (RoB v. 2.0), and the quality of evidence was evaluated by the GRADE system. A total of 766 studies were identified in the databases, of which 7 met the eligibility criteria. None of the studies indicated the occurrence of adverse reactions with vitamin D supplementation in any administered dosage. Supplemented patients had a significant reduction in serum TSH levels compared to the control group (mean difference $=-0.180(95 \% \mathrm{Cl}[-0.316$ to -0.045$]), \mathrm{p}=$ 0.009 ), suggesting that thyroid function was more controlled in the intervention group. However, for the other outcomes, no statistically significant differences were observed between the groups. Additionally, most of included articles $(n=5 / 7)$ had some concerns or high risk of bias, and the quality of evidence revealed a moderate confidence for almost all outcomes; so the results must be interpreted with caution. Thus, more consistent, and robust clinical trials need to be carried out to confirm the efficacy of vitamin D supplementation in patients with HD.
\end{abstract}

Keywords: Hashimoto's Disease. Systematic Review. Meta-Analysis. Vitamin D.

\section{How to cite}

Santos JMMF, Alencar EV, Martins ECO, Ossoski CA, Bonetti AF. Vitamin D in patients with Hashimoto's disease: a systematic review and meta-analysis. Rev Ciênc Farm Básica Apl. 2022;43:e758. https://doi.org/10.4322/2179-443X.0758

Financial support: This research did not receive any specific grant from funding agencies in the public, commercial, or not-for-profit sectors. Conflicts of interest: None declared.

The study was carried out at Faculdades Pequeno Príncipe, Curitiba, PR, Brasil.

Received on October 17, 2021. Accepted on November 03, 2021 


\section{INTRODUCTION}

Hashimoto's disease (HD) is a chronic autoimmune thyroid disease caused by genetic and environmental conditions, characterized by the production of specific antibodies against antigens of the thyroid gland (thyroperoxidase and thyroglobulin) ${ }^{1-3}$. This disease was first described in 1912 by Hakaru Hashimoto and represents the most common cause of hypothyroidism in adults, mainly in developed countries ${ }^{1-5}$.

Anti-thyroperoxidase (Anti-TPO) and anti-thyroglobulin (Anti-Tg) antibodies attack the thyroid follicles, impairing their functionality ${ }^{2,6}$. In this sense, the production of the thyroid hormones triiodothyronine (T3) and thyroxine (T4) is compromised, with a compensatory increase in thyroid-stimulating hormone (TSH) levels ${ }^{2,6}$. The diagnosis and monitoring of the evolution of this disease are basically carried out by measuring the aforementioned antibodies and thyroid hormones, as well as by conducting thyroid imaging examinations $\mathbf{s}^{2,6}$.

Similar to other etiologies of hypothyroidism, the main signs and symptoms are tiredness, drowsiness, weight gain, constipation, dry skin, hair loss, and hypercholesterolemia, ${ }^{5,6}$. Additionally, the treatment of HD is initially based on the administration of low doses of fasting levothyroxine (12.5 to $25 \mathrm{mcg}$ ), with subsequent dosage adjustments according to the results of laboratory tests ${ }^{6,7}$. The goals of therapy are symptom relief and maintenance of serum TSH levels within the reference range ${ }^{5-7}$.

Recent clinical and observational studies have suggested that vitamin D supplementation, associated with standard therapy (levothyroxine), can contribute to the control of this and other autoimmune diseases, such as rheumatoid arthritis and systemic lupus erythematosus, due to its immunomodulatory action ${ }^{8-12}$. Previous studies have shown that vitamin $D$ can suppress the autoimmune reaction and consequently reduce the serum levels of autoantibodies ${ }^{13-22}$. Additionally, recent meta-analyses found that patients with HD are more likely to have reduced serum vitamin $D$ levels compared to healthy patients ${ }^{23,24}$. However, these meta-analyses did not evaluate the efficacy and safety of the vitamin $D$ supplementation in patients with $\mathrm{HD}$, once the authors aimed to establish the association between the serum levels in these patients compared to healthy people ${ }^{23,24}$.

So, it is not clear whether vitamin D supplementation is, in fact, effective and safe in the treatment of $H D^{24}$. Additionally, current guidelines did not describe the possibility of vitamin $D$ supplementation in patients with $\mathrm{HD}^{2,6}$. Thus, new studies, especially systematic reviews, and meta-analyses, are necessary. Moreover, it is known that such studies have a better level of evidence compared to primary studies, as they group, synthesize, and allow a more robust critical assessment on a given subject ${ }^{25}$. Therefore, this study aimed to evaluate the efficacy and safety of vitamin D supplementation in patients with HD, through a systematic review and meta-analysis.

\section{METHODS}

\subsection{Planning the review}

This systematic review was performed according to the Preferred Reporting Items for Systematic Reviews and Meta-Analyses (PRISMA) and the Cochrane Collaboration recommendations ${ }^{25,26}$. This review was submitted to the PROSPERO platform (CRD42021235430).

All steps of this study, including the study selection (screening and full text appraisal), data extraction, and the quality analysis were performed by two authors independently, with a third author to solve discrepancies.

\subsection{Searches and study selection}

Systematic searches were conducted in PubMed (which included MEDLINE and PubMed Central databases), Scopus, and Web of Science, without limits on timeframe or language (updated on $10^{\text {th }}$ October 2021). To extract the studies from these databases and remove the duplicated articles, we use the Endnote ${ }^{\circledR}$ software (v. 7.0). The full search strategies are 
available in Table S1 of the Supplementary Material (DOI 10.17605/OSF.IO/9TH2G). Additionally, the reference lists of the included studies were manually searched to retrieve other relevant records. Titles and abstracts of the articles identified during the database searches and on manual search were screened for eligibility, and relevant studies were read in full. This process was performed in standardized sheets on Microsoft Excel ${ }^{\circledR}$. The PICOS (population, intervention, control, outcomes, and study design) model was used to select potential studies for data extraction:

- P (population): patients diagnosed with Hashimoto's Disease (regardless of age).

- I (intervention): patients supplemented with vitamin D (associated or not with levothyroxine).

- C (control): patients not supplemented with vitamin D, placebo, or patients using other therapies.

- O (outcomes): serum levels of thyroid hormones (T3, T4, TSH) and antibodies (Anti-TPO and Anti-Tg) and adverse reactions.

- S (study design): randomized clinical trials.

Other study designs, reprint (i.e same article published in more than one journal), articles published in non-Roman characters, congress abstracts, theses and dissertations, and studies that did not assess the outcomes of interest were excluded. Studies that included pregnancy patients or other thyroid diseases (such as Graves' disease) were also excluded.

\subsection{Data extraction and quality assessment}

The following data were extracted by two reviewers independently, in standardized sheets on Microsoft Excel: (i) study and baseline characteristics (authors names, year of publication, country, sample size, patient age, trial duration); (ii) evaluated treatments, with detail (dosage, duration of treatment); (iii) clinical outcome results (serum levels of thyroid hormones (T3, T4, TSH) and antibodies (Anti-TPO Ab and Anti-Tg Ab) and adverse reactions). The risk of bias of the included articles was evaluated according to the Cochrane Collaboration's tool (RoB version 2.0), by two reviewers independently ${ }^{25}$. Additionally, the quality of evidence was assessed using the Grading of Recommendations Assessment, Development and Evaluation (GRADE) Working Group ${ }^{27}$.

\subsection{Statistical analyses}

Pairwise meta-analyses of randomized clinical trials were performed in Comprehensive MetaAnalysis v 2.2 software (Biostat, Englewood, NJ, USA). Meta-analyses for the following outcomes were performed: serum levels of T3, T4, TSH, Anti-TPO Ab, and Anti-Tg Ab. The random-effects model and the inverse variance method were used to interpolate the effect measures of each study, with a 95\% confidence interval $(\mathrm{Cl})$. The effect sizes were the difference in means or standardized mean difference, considering that all the outcomes of interest were continuous. Results with $p$ values of $<0.05$ were considered statistically significant. The meta-analyses were expressed as forest plots. The heterogeneity between the assays was estimated using the relative index of inconsistency 12 (I2>50\% indicates high and significant heterogeneity). The sensitivity analysis consisted of the hypothetical sequential removal of studies from the metaanalysis. Changes in statistical methods and models were also tested.

\section{RESULTS}

The systematic search of the databases identified 766 records. After removing duplicates, 492 articles were selected for screening, of which 439 were excluded and 53 were read in full. A further 46 records were excluded at this point, and 7 had their data extracted ${ }^{7,28-33}$ (Figure 1). The studies excluded after full-text reading are reported in Table $\mathrm{S} 2$ of the Supplementary Material, with justifications (DOI 10.17605/OSF.IO/9TH2G). 


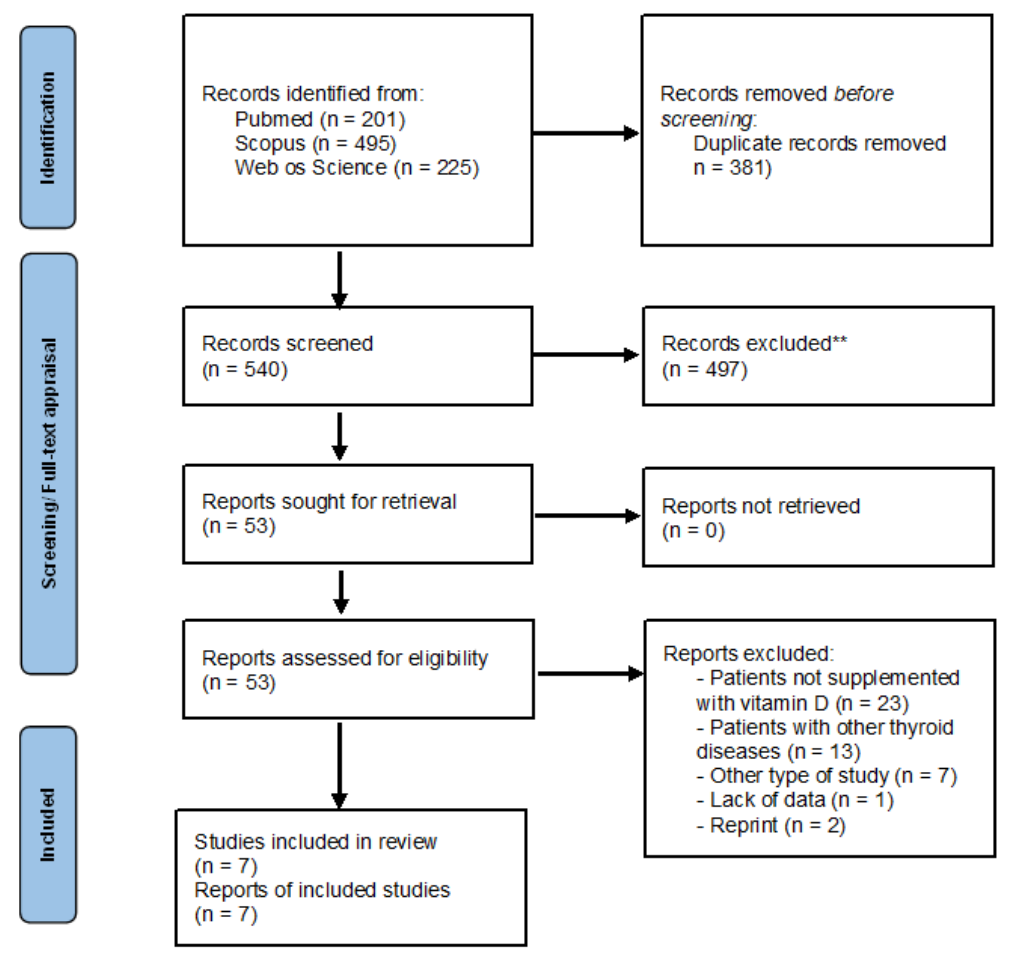

Figure 1. Flowchart of the systematic review.

As shown in Table 1, most of the included studies were multicentric and were published between 2016 and 2019. This systematic review included 566 patients, most of whom were female $(71 \%)$, with ages ranging from 28 to 45 years. The dose of vitamin D supplementation ranged from 1,000 IU per day to 60,000 IU per week. A placebo was the comparator in three studies $^{7,28,30}$ and two studies used active comparators ${ }^{29,32}$, while the other two studies did not use any comparator ${ }^{31,33}$. The use of levothyroxine was present in most studies; however, two of the studies did not report this information ${ }^{30,32}$. The shortest duration of vitamin $D$ supplementation was 4 weeks, and the longest was 24 weeks.

Table 1. Baseline characteristics of the included studies

\begin{tabular}{|c|c|c|c|c|c|c|c|c|c|}
\hline $\begin{array}{l}\text { Author, } \\
\text { year }\end{array}$ & Country & Interventions & $\begin{array}{c}\text { Dose of } \\
\text { Vitamin } \\
\text { D } \\
\end{array}$ & $\begin{array}{c}\text { Duration } \\
\text { of } \\
\text { treatment }\end{array}$ & $\begin{array}{l}\text { Dosage of } \\
\text { Vitamin D }\end{array}$ & $\mathbf{N}$ & $\begin{array}{c}\text { Numbers of } \\
\text { patients using } \\
\text { Levothyroxine }\end{array}$ & Age (years)* & $\begin{array}{c}\text { Men (n, } \\
\%)\end{array}$ \\
\hline \multirow{2}{*}{$\begin{array}{c}\text { Anaraki, } \\
2017^{28}\end{array}$} & \multirow{2}{*}{ Iran } & Vitamin D & $50.000 \mathrm{IU}$ & 12 Weeks & Once a week & 30 & 13 & 43.55 (1.56) & $9(30)$ \\
\hline & & Placebo & NR & 12 Weeks & Once a week & 26 & 8 & $44.12(1.56)$ & $11(41)$ \\
\hline \multirow{2}{*}{$\begin{array}{c}\text { Chahardoli, } \\
2019^{7}\end{array}$} & \multirow{2}{*}{ Iran } & Vitamin D & $50.000 \mathrm{IU}$ & 12 Weeks & Once a week & 21 & 21 & $36.4(5.2)$ & $0(0)$ \\
\hline & & Placebo & NR & 12 Weeks & Once a week & 21 & 21 & $35.9(7.8)$ & $0(0)$ \\
\hline \multirow{2}{*}{$\begin{array}{c}\text { Chaudhary, } \\
2016^{29}\end{array}$} & \multirow[b]{2}{*}{ India } & Vitamin D & $60.000 \mathrm{IU}$ & 08 Weeks & Once a week & 50 & 50 & $28.48(6.57)$ & $11(22)$ \\
\hline & & $\begin{array}{l}\text { Calcium } \\
\text { carbonate }\end{array}$ & $1.250 \mathrm{mg}$ & 08 Weeks & Once a day & 50 & 50 & $27.86(7.29)$ & $13(26)$ \\
\hline \multirow{3}{*}{$\begin{array}{l}\text { Knusten, } \\
2017^{30}\end{array}$} & \multirow{3}{*}{ Norway } & Vitamin D & $1.000 \mathrm{IU}$ & 16 Weeks & Once a day & 75 & NR & $\begin{array}{c}W=35(7.5) / \\
M=40(9.1)\end{array}$ & $26(31)$ \\
\hline & & Vitamin D & $400 \mathrm{IU}$ & 16 Weeks & Once a day & 69 & NR & $\begin{array}{c}W=36(7.8) / \\
M=40(6.6)\end{array}$ & $24(28)$ \\
\hline & & Placebo & NR & 16 Weeks & Once a day & 71 & NR & $\begin{array}{c}W=38(7.6) / \\
M=39(7.8)\end{array}$ & $19(23)$ \\
\hline $\begin{array}{c}\text { Krysiak, } \\
2017^{31}\end{array}$ & Poland & No intervention & NR & 24 Weeks & Once a day & 18 & 18 & 35 & $0(0)$ \\
\hline
\end{tabular}


Table 1. Continued...

\begin{tabular}{|c|c|c|c|c|c|c|c|c|c|}
\hline $\begin{array}{c}\text { Author, } \\
\text { year }\end{array}$ & Country & Interventions & $\begin{array}{c}\text { Dose of } \\
\text { Vitamin } \\
\text { D }\end{array}$ & $\begin{array}{c}\text { Duration } \\
\text { of } \\
\text { treatment }\end{array}$ & $\begin{array}{l}\text { Dosage of } \\
\text { Vitamin D }\end{array}$ & $\mathbf{N}$ & $\begin{array}{l}\text { Numbers of } \\
\text { patients using } \\
\text { Levothyroxine }\end{array}$ & Age (years)* & $\begin{array}{c}\text { Men (n, } \\
\%)\end{array}$ \\
\hline \multirow{3}{*}{$\begin{array}{c}\text { Krysiak, } \\
2018^{32}\end{array}$} & \multirow{3}{*}{ Poland } & Vitamin D & $2.000 \mathrm{IU}$ & 24 Weeks & Once a day & 16 & 16 & 34 & $0(0)$ \\
\hline & & Vitamin D & $4.000 \mathrm{IU}$ & 24 Weeks & Once a day & 20 & NR & $35(8)$ & $20(100)$ \\
\hline & & Selenomethionine & $200 \mu g$ & 24 Weeks & Once a day & 17 & NR & $34(7)$ & $17(100)$ \\
\hline \multirow[b]{2}{*}{$\begin{array}{l}\text { Simsek, } \\
2016^{33}\end{array}$} & \multirow[b]{2}{*}{ Turkey } & Vitamin D & $1.000 \mathrm{IU}$ & 04 Weeks & Once a day & 46 & 5 & $35.8(12)$ & $9(20)$ \\
\hline & & $\begin{array}{l}\text { Exposure to the } \\
\text { sun and diet } \\
\text { control }\end{array}$ & NA & 04 Weeks & Once a day & 36 & 1 & 39.7 (12.6) & $5(14)$ \\
\hline
\end{tabular}

* Data are expressed as mean and standard deviation.

Legend: N: number of patients; NR: not reported; M - men; IU: International Units; W: women.

Table 2 details the results of the selected studies, including the results of antibodies (AntiTPO, Anti-Tg), thyroid hormones (TSH, T3, and T4), and serum levels of 25-hydroxyvitamin D (25 OHD). The studies pointed that the vitamin D was safe, once no adverse reactions were observed. However, not all studies reported all outcomes of interest.

Table 2 - Efficacy results of the included studies

\begin{tabular}{|c|c|c|c|c|c|c|c|}
\hline $\begin{array}{c}\text { Author, } \\
\text { year }\end{array}$ & Interventions & $\begin{array}{l}\text { Anti-TPO } \\
\text { (UI/mL)* }\end{array}$ & $\begin{array}{l}\text { Anti-Tg } \\
\text { U/mL* }\end{array}$ & $\begin{array}{c}\text { TSH } \\
(\mu \mathrm{IU} / \mathrm{ml})^{*}\end{array}$ & $\mathrm{~T} 3(\mathrm{ng} / \mathrm{ml})^{*}$ & $\begin{array}{c}\mathrm{T} 4 \\
\text { (ng/ml)* }\end{array}$ & $25(\mathrm{OH}) \mathrm{D}^{*}$ \\
\hline \multirow{2}{*}{$\begin{array}{l}\text { Anaraki, } \\
2017^{28}\end{array}$} & Vitamin D & 734 (102.93) & NR & NR & $3.79(0.26)$ & NR & $9.01(0.09) \mathrm{mg} / \mathrm{dL}$ \\
\hline & Placebo & $\begin{array}{c}750.03 \\
(108.71)\end{array}$ & NR & NR & $\begin{array}{c}4.31(0.27) \\
\mathrm{ng} / \mathrm{L}\end{array}$ & NR & $8.85(0.13) \mathrm{mg} / \mathrm{dL}$ \\
\hline \multirow[t]{2}{*}{$\begin{array}{c}\text { Chahardoli, } \\
2019^{7}\end{array}$} & Vitamin D & 118.1 (97.9) & $\begin{array}{c}140.2 \\
(134.3)\end{array}$ & $1.83(1.4)$ & $1.28(0.35)$ & $\begin{array}{c}0.94 \\
(0.15)\end{array}$ & NR \\
\hline & Placebo & $181.6(122.5)$ & $\begin{array}{c}176.7 \\
(167.1)\end{array}$ & $2.77(1.9)$ & $1.31(0.34)$ & $\begin{array}{c}0.86 \\
(0.12)\end{array}$ & NR \\
\hline \multirow[t]{2}{*}{$\begin{array}{c}\text { Chaudhary, } \\
2016^{29}\end{array}$} & Vitamin D & 387 (1146) & NR & $\begin{array}{c}3.16 \\
(2.07)\end{array}$ & NR & $\begin{array}{c}1.27 \\
(0.20)\end{array}$ & $95.52(124) \mathrm{nmol} / \mathrm{L}$ \\
\hline & $\begin{array}{l}\text { Calcium } \\
\text { carbonate }\end{array}$ & $553.5(1002)$ & NR & $\begin{array}{c}3.39 \\
(2.19)\end{array}$ & NR & $\begin{array}{c}1.30 \\
(0.14)\end{array}$ & $\begin{array}{c}41.61(100.06) \\
\mathrm{nmol} / \mathrm{L}\end{array}$ \\
\hline \multirow[t]{3}{*}{$\begin{array}{c}\text { Knusten, } \\
2017^{30}\end{array}$} & Vitamin D & $147(317)$ & NR & $2.2(2.9)$ & NR & $\begin{array}{c}1.24 \\
(0.15)\end{array}$ & NR \\
\hline & Vitamin D & 81 (157) & NR & $1.7(0.8)$ & NR & $\begin{array}{c}1.28 \\
(0.13)\end{array}$ & NR \\
\hline & Placebo & 105 (217) & NR & $2.3(2.4)$ & NR & $\begin{array}{c}1.25 \\
(0.13)\end{array}$ & NR \\
\hline \multirow[t]{2}{*}{$\begin{array}{c}\text { Krysiak, } \\
2017^{31}\end{array}$} & No intervention & $1410(425)$ & $1212(385)$ & $4.5(1.0)$ & $3.8(0.6)$ & $\begin{array}{c}1.1 \\
(0.17)\end{array}$ & $47(12) \mathrm{ng} / \mathrm{ml}$ \\
\hline & Vitamin D & $955(358)$ & $934(415)$ & $4.1(1.5)$ & $4.2(0.6)$ & $\begin{array}{c}1.19 \\
(0.17)\end{array}$ & $64(10) \mathrm{ng} / \mathrm{ml}$ \\
\hline \multirow{2}{*}{$\begin{array}{c}\text { Krysiak, } \\
2018^{32}\end{array}$} & Vitamin D & $638(211)$ & $2.7(0.7)$ & $3.6(0.6)$ & NR & NR & NR \\
\hline & Selenomethionine & $649(783)$ & $2.6(0.6)$ & $3.8(0.8)$ & NR & NR & NR \\
\hline \multirow{2}{*}{$\begin{array}{c}\text { Simsek, } \\
2016^{33}\end{array}$} & Vitamin D & $210(7.6-600)$ & NR & $1.2(0.4)$ & NR & NR & NR \\
\hline & $\begin{array}{l}\text { Exposure to the } \\
\text { sun and diet } \\
\text { control }\end{array}$ & $166(7.9-534)$ & NR & $1.4(1.3)$ & NR & NR & NR \\
\hline
\end{tabular}

* Data are expressed as mean and standard deviation, except to the study of Simsek, 2016 (the Anti-TPO is expressed in mean, minimum and maximum values). Legend: Anti-TPO: Thyroid Peroxidase Antibody; Anti-Tg: Antithyroglobulin Antibody; TSH: Thyroid-stimulating Hormone; T3: Triiodothyronine; T4: Thyroxine; NR: not reported. 
The risk of bias assessment revealed that most studies had high overall risk or some concerns $(n=5 / 7 ; 71.42 \%)^{7,28,29,31,32}$. The main domains responsible for increasing the risk of bias were randomization process, deviations from the intended interventions, and measurement of outcome. In general, these studies did not report the randomization and allocation concealment process in detail and did not report the results completely. Only two studies had a low risk of bias ${ }^{30,33}$ (Figure 2).

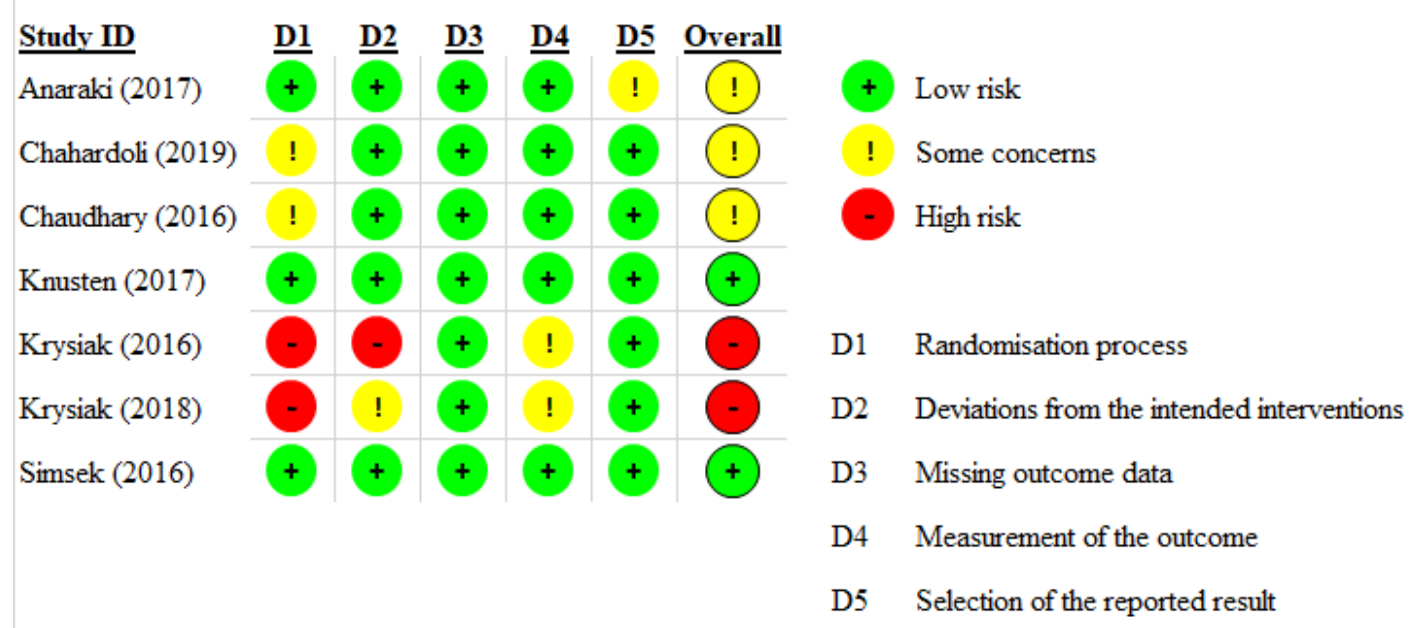

Figure 2 - Risk of bias of included studies

Considering the results reported by the seven primary studies included in this systematic review, it was possible to construct four meta-analyses for the following outcomes: TSH, T3, T4, Anti-TPO, and Anti-Tg. For the study by Knutsen et al. ${ }^{30}$, it should be noted that the patients that received vitamin D 1,000 IU per day were considered as the intervention group.

The group that received vitamin $\mathrm{D}$ (intervention group) had statistically significantly lower TSH values compared to the control group (mean difference $=-0.180(95 \% \mathrm{Cl}[-$ 0.316 to -0.045$]), p=0.009$ ). This result suggests that thyroid function was more controlled in the intervention group than in the control group, but only in terms of TSH values (Figure 3). Additionally, this meta-analysis showed null heterogeneity $(12=0 \%$, $p=0.575)$.

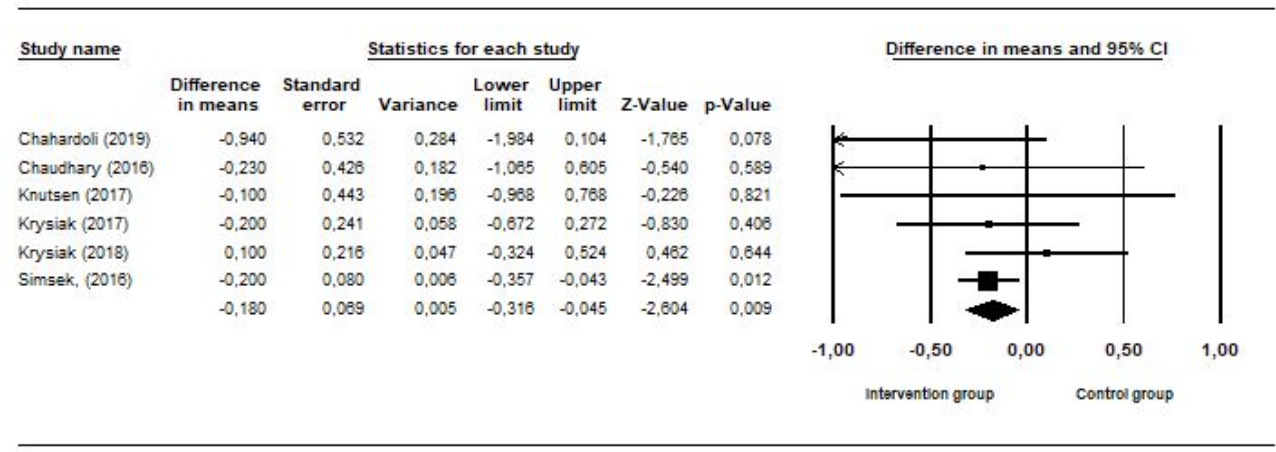

$12=0 \%, p=0.575$

Figure 3. Forest plot for the TSH outcome $(\mathrm{mUl} / \mathrm{mL})$. 
In parallel, there was no statistically significant difference between the groups regarding the values of T4 (mean difference $=-0.024$ (95\% Cl [-0.058 to 0.010]), $p=0.171$ ) (Figure 4). The heterogeneity of this meta-analysis was also null $(12=0 \%)$.

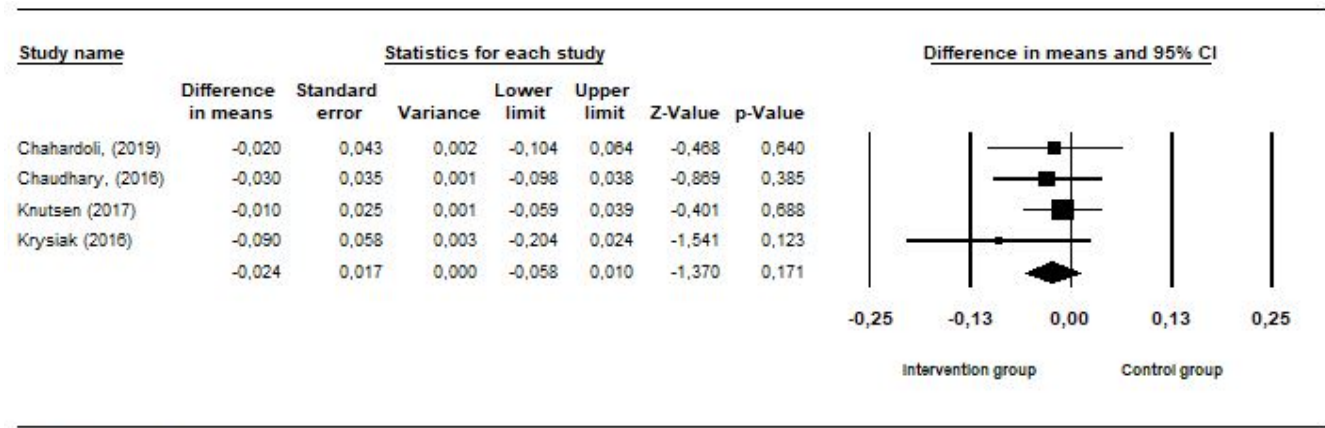

$12=0 \%, p=0.652$.

Figure 4. Forest plot for the T4 outcome ( $\mu \mathrm{g} / \mathrm{dL})$.

For the other outcomes (Anti-Tg, Anti-TPO, and T3), the meta-analyses did not reveal statistically significant differences between the groups, and the heterogeneity was high in all of them (Figures 5 to 7). Few studies could be included for the T3 meta-analysis $(n=3)$, since the authors failed to report all their results (mean difference $=-0.313(95 \%$ $\mathrm{Cl}[-0.664$ to 0.037$]), \mathrm{p}=0.080,12=84.22 \%)$. The study by Anaraki et al. ${ }^{28}$ was mainly responsible for the high heterogeneity; however, even with its withdrawal, the 12 still remained high $(12=64 \%)$.

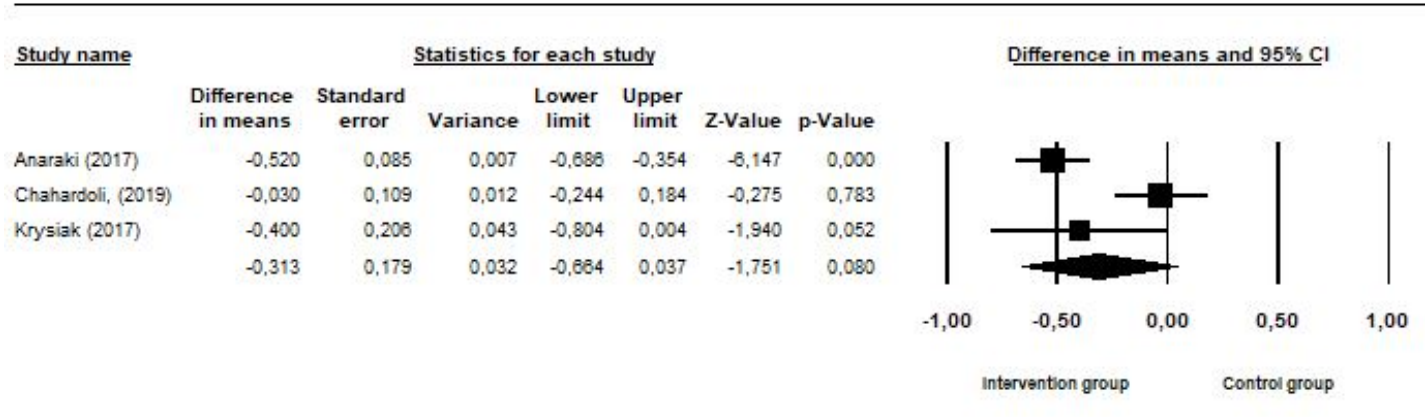

$12=84.22 \%, p=0.002$

Figure 5. Forest plot for the T3 outcome $(\mathrm{ng} / \mathrm{mL})$.

The pooled effect size (standardized mean difference - SMD) for the Anti-Tg outcome was 0.187 ( $\mathrm{Cl} 95 \%$ [-0.309 to 0.423], $\mathrm{p}=0.760$ ), with a high heterogeneity (Figure 6). The sensitivity analysis showed that the study by Krysiak et al. ${ }^{31}$ was the main study responsible for the heterogeneity in the Anti-Tg meta-analysis since its removal led to an 12 result of $33 \%$. Similarly, for the Anti-TPO outcome, there was no difference between the groups (SMD $0.185(\mathrm{Cl} 95 \%$ [-0.319 to 0.407], $\mathrm{p}=0.812), 12=67.15 \%$ ) (Figure 7). The study that most contributed to the high heterogeneity of this metaanalysis was that of Krysiak et al. ${ }^{32}$, because the 12 result was equal to $11.03 \%$ when it was removed from the analysis. 


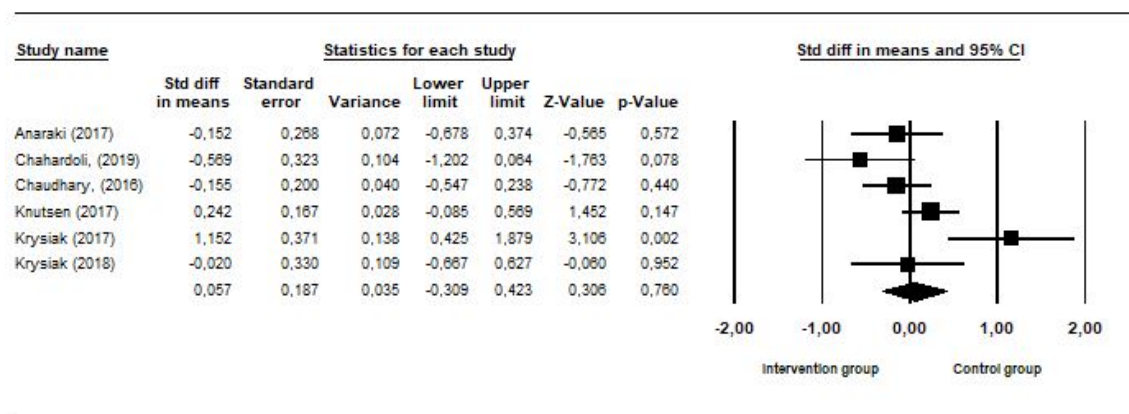

$12=67.71, p=0.008$

Figure 6. Forest plot for the Anti-Tg outcome (IU/mL).

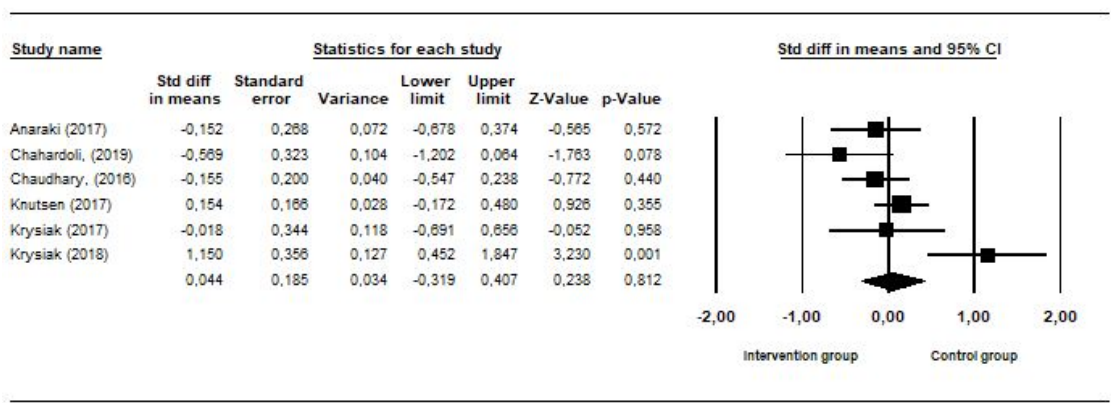

$12=67.15, p=0.009$

Figure 7. Forest plot for the Anti-TPO outcome (UI/mL).

Table 3 presents the results of the quality of evidence assessment (GRADE) for the evaluated outcomes: serum levels of thyroid hormones (T3, T4, TSH) and antibodies (Anti-TPO $\mathrm{Ab}$ and Anti-Tg Ab). In most cases, the quality of evidence revealed a moderate certainty, especially because of the risk of bias assessment. For the T3 outcome, the confidence was very low, because of other reasons too: inconsistency, once the heterogeneity was high, and imprecision, due to the wide confidence interval.

Table 3 - Evidence quality assessment (GRADE)

\begin{tabular}{|c|c|c|c|c|c|c|c|}
\hline \multicolumn{7}{|c|}{ Certainty assessment } & \multirow[b]{2}{*}{ Certainty } \\
\hline $\begin{array}{c}\text { N. of } \\
\text { studies }\end{array}$ & $\begin{array}{l}\text { Study } \\
\text { design }\end{array}$ & $\begin{array}{c}\text { Risk of } \\
\text { bias }\end{array}$ & Inconsistency & $\begin{array}{l}\text { Indirect } \\
\text { evidence }\end{array}$ & Imprecision & $\begin{array}{c}\text { Other } \\
\text { considerations }\end{array}$ & \\
\hline \multicolumn{8}{|c|}{ Outcome: TSH } \\
\hline 6 & $\mathrm{RCT}$ & serious $^{a}$ & no serious & no serious & no serious & None & $\begin{array}{l}\oplus \oplus \oplus \bigcirc \\
\text { Moderate }\end{array}$ \\
\hline \multicolumn{8}{|c|}{ Outcome: T4 } \\
\hline 4 & $\mathrm{RCT}$ & serious $^{a}$ & no serious & no serious & no serious & None & $\begin{array}{l}\oplus \oplus \oplus \bigcirc \\
\text { Moderate }\end{array}$ \\
\hline \multicolumn{8}{|c|}{ Outcome: T3 } \\
\hline 3 & $\mathrm{RCT}$ & serious $^{a}$ & serious $^{\mathrm{b}}$ & no serious & serious $^{c}$ & None & $\begin{array}{l}\oplus \bigcirc \bigcirc \bigcirc \\
\text { Very Low }\end{array}$ \\
\hline \multicolumn{8}{|c|}{ Outcome: Anti-TG } \\
\hline 6 & $\mathrm{RCT}$ & serious $^{a}$ & no serious & no serious & no serious & None & $\begin{array}{l}\oplus \oplus \oplus \bigcirc \\
\text { Moderate }\end{array}$ \\
\hline \multicolumn{8}{|c|}{ Outcome: Anti-TPO } \\
\hline 6 & $\mathrm{RCT}$ & serious $^{a}$ & no serious & no serious & no serious & None & $\begin{array}{c}\oplus \oplus \oplus \bigcirc \\
\text { Moderate }\end{array}$ \\
\hline
\end{tabular}

Explanations: N: number. a. Most studies had some concerns or high risk of bias. b. High heterogeneity. c. Wide confidence interval 


\section{DISCUSSION}

The present systematic review and meta-analysis demonstrated that vitamin $D$ supplementation promoted a serum reduction of TSH hormone in patients with Hashimoto's Disease (HD), revealing a better thyroid control compared to non-supplemented patients. However, this finding requires confirmation, since the intervention and control groups did not show statistically significant differences for the other tested substances (T3, T4, Anti-Tg, and Anti-TPO). Safety data were scarce, although the included studies did not indicate the occurrence of clinically important adverse events, suggesting that this vitamin is safe. Additionally, most studies had some concerns or high risk of bias according to the Rob 2 tool $(n=5 / 7)$, and the certainty of the evidence was moderate in most cases, according to the GRADE system; so the results of the meta-analyses should be interpreted with caution.

It is known that the reduction of TSH combined with an increase of T4 and T3 in patients with uncontrolled hypothyroidism is associated with good thyroid control ${ }^{2,6}$. However, the authors of the seven included primary studies did not report all the outcomes of interest, and some meta-analyses were built with only a few studies. Thus, further well-reported randomized clinical trials are necessary to confirm these findings.

We highlight that four of the six studies included in the TSH meta-analysis reported the use of levothyroxine associated with vitamin $D^{7,29,31,33}$. Thus, the importance of hormone replacement for thyroid control cannot be excluded. However, the two studies ${ }^{30,31}$ that did not report the use of levothyroxine revealed a significant reduction in TSH levels, suggesting that further studies need to be carried out to explore the real efficacy of vitamin D in HD.

Therefore, due to the scarcity of studies about this topic, the present systematic review questions whether vitamin $D$ supplementation is necessary for all patients who have HD, or whether it is only necessary for those who have a deficiency or insufficiency of this vitamin. In the present study, it was not possible to clarify such this question, due to the limited evidence in the included studies, since only three of them mentioned the serum vitamin $D$ dosage in the initial recruitment of the participants ${ }^{28,29,31}$. Additionally, it is still unclear which dose of vitamin $\mathrm{D}$ is ideal for these patients, since the included studies were heterogeneous in terms of the dosage.

Recently, two systematic reviews of randomized clinical trials about vitamin D in HD have been published ${ }^{24,34}$. One of them did not assess vitamin supplementation in patients with this disease but established a correlation between serum vitamin $D$ levels and autoimmune hypothyroidism. Twenty-two studies were included in a pairwise meta-analysis, which revealed that patients with autoimmune thyroid diseases (including HD and Graves' disease) had lower levels of vitamin $\mathrm{D}(\mathrm{SMD}=-0.99[95 \% \mathrm{Cl}-1,31$ to -0.66$])$ and were more likely to have this vitamin deficiency (odds ratio $(\mathrm{OR})=2.99[95 \% \mathrm{Cl} 1.88$ to 4.74]) compared to healthy patients ${ }^{24}$.

In parallel, the other systematic review ${ }^{33}$ showed statistically significant differences for the levels of autoantibodies (Anti-Tg and Anti-TPO) between the intervention (vitamin D) and control (not supplemented) groups, in contrast to the present study, which did not identify differences for these outcomes. However, the patients selected in the study of Wang et al. ${ }^{34}$ had HD or Graves' disease, revealing a more heterogeneous population compared to the present systematic review, which could compromise the results of their analysis. Additionally, despite including patients with two different thyroid diseases, the aforementioned systematic review selected fewer articles for analysis $(n=6)$, with a total of 344 patients, and did not evaluate other outcomes of interest, such as serum levels of thyroid hormones. Therefore, the present study contemplates more concrete and updated results about a more homogeneous population.

Additionally, a previous systematic review and meta-analysis of observational studies revealed a significant association between lower serum vitamin $D$ and $H D$, compared with healthy patients (Cohen's $d-0.62(95 \% \mathrm{Cl}-0.89,-0.34 ; \mathrm{p}<0.0001)$. Patients with HD had an OR of $3.21(1.94-5.3 ; p<0.0001)$ for vitamin $D$ deficiency (cut-off $20 \mathrm{ng} / \mathrm{mL}$ ) against healthy 
controls. However, this study did not evaluate the impact of the vitamin D supplementation on disease control, in terms of improvement in serum levels of thyroid hormones ${ }^{23}$.

The present study has some limitations. Insufficient reporting of primary study results, such as the absence of the standard deviation of thyroid hormone averages, prevented all studies of the systematic review from being included in some meta-analyses. Additionally, it is not clear whether patients with HD used vitamin D only if the dosage of this substance was insufficient, as this information was not provided in all included studies. We also did not include grey literature as additional source on this review. However, despite these limitations, the present study corroborates previous investigations that point to a positive relationship between vitamin $\mathrm{D}$ supplementation in $\mathrm{HD}$, although confirmation is necessary by conducting good-quality randomized clinical trials.

\section{CONCLUSION}

Considering the results obtained in this systematic review and meta-analysis, it is observed that vitamin D supplementation led to a decrease in TSH in patients with HD. However, the results of the other thyroid hormones did not show statistically significant differences, revealing conflicting evidence about the benefit of vitamin D in these patients. Additionally, the results of the meta-analyses should be interpreted with caution, once most of the included studies had some concerns or high risk of bias and the quality of evidence revealed a moderate confidence in most cases. Thus, consistent, and robust randomized clinical trials need to be carried out to confirm the real clinical implications of this vitamin in patients with HD.

\section{ACKNOWLEDGMENTS}

The authors thank the Pequeno Príncipe College for allowing this work to have been carried out successfully.

\section{REFERENCES}

1. Caturegli P, De Remigis A, Rose NR. Hashimoto thyroiditis: clinical and diagnostic criteria. Autoimmun Rev. 2014;13(4-5):391-7. http://dx.doi.org/10.1016/j.autrev.2014.01.007. PMid:24434360.

2. Garber JR, Cobin RH, Gharib H, Hennessey JV, Klein I, Mechanick JI, Pessah-Pollack R, Singer PA, Woeber KA. Clinical practice guidelines for hypothyroidism in adults: cosponsored by the American Association of Clinical Endocrinologists and the American Thyroid Association. Endocr Pract. 2012;18(6):988-1028. http://dx.doi.org/10.4158/EP12280.GL. PMid:23246686.

3. Hiromatsu $Y$, Satoh H, Amino N. Hashimoto's thyroiditis: history and future outlook. Hormones (Athens). 2013;12(1):12-8. http://dx.doi.org/10.1007/BF03401282. PMid:23624127.

4. Liontiris MI, Mazokopakis EE. A concise review of Hashimoto thyroiditis (HT) and the importance of iodine, selenium, vitamin $\mathrm{D}$ and gluten on the autoimmunity and dietary management of HT patients.Points that need more investigation. Hell J Nucl Med. 2017;20(1):51-6. PMid:28315909.

5. McDermott MT. Hypothyroidism. Ann Intern Med. 2020;173(1):ITC1-16. http://dx.doi.org/10.7326/AITC202007070. PMid:32628881.

6. Brenta G, Vaisman M, Sgarbi JA, Bergoglio LM, Andrada NC, Bravo PP, Orlandi AM, Graf H. Clinical practice guidelines for the management of hypothyroidism. Arq Bras Endocrinol Metabol. 2013;57(4):265-91. http://dx.doi.org/10.1590/S0004-27302013000400003. PMid:23828433.

7. Chahardoli R, Saboor-Yaraghi AA, Amouzegar A, Khalili D, Vakili AZ, Azizi F. Can supplementation with vitamin D modify thyroid autoantibodies (Anti-TPO Ab, Anti-Tg Ab) and thyroid profile (T3, T4, TSH) in Hashimoto's thyroiditis? A double blind, randomized clinical trial. Horm Metab Res. 2019;51(5):296-301. http://dx.doi.org/10.1055/a-0856-1044. PMid:31071734. 
8. Harrison SR, Li D, Jeffery LE, Raza K, Hewison M, Vitamin D. Autoimmune disease and rheumatoid arthritis. Calcif Tissue Int. 2020;106(1):58-75. http://dx.doi.org/10.1007/s00223-019-00577-2. PMid:31286174.

9. Islam MA, Khandker SS, Alam SS, Kotyla P, Hassan R. Vitamin D status in patients with systemic lupus erythematosus (SLE): a systematic review and meta-analysis. Autoimmun Rev. 2019;18(11):102392. http://dx.doi.org/10.1016/j.autrev.2019.102392. PMid:31520805.

10. Lee $\mathrm{YH}$, Bae SC. Vitamin D level in rheumatoid arthritis and its correlation with the disease activity: a meta-analysis. Clin Exp Rheumatol. 2016;34(5):827-33. PMid:27049238.

11. Sassi F, Tamone C, D'Amelio P, Vitamin D. Nutrient, hormone, and immunomodulator. Nutrients. 2018;10(11):1656. http://dx.doi.org/10.3390/nu10111656. PMid:30400332.

12. Watad A, Neumann SG, Soriano A, Amital H, Shoenfeld Y. Vitamin D and Systemic Lupus Erythematosus: myth or Reality? Isr Med Assoc J. 2016;18(3-4):177-82. PMid:27228639.

13. Aktaş H. Vitamin B12 and Vitamin D levels in patients with autoimmune hypothyroidism and their correlation with anti-thyroid peroxidase antibodies. Med Princ Pract. 2020;29(4):364-70. http://dx.doi.org/10.1159/000505094. PMid:31779003.

14. Altieri B, et al. Does vitamin D play a role in autoimmune endocrine disorders? A proof of concept. Rev Endocr Metab Disord. 2017;18(3):335-46. http://dx.doi.org/10.1007/s11154-016-9405-9. PMid:28070798.

15. Botelho IMB, Moura Neto A, Silva CA, Tambascia MA, Alegre SM, Zantut-Wittmann DE. Vitamin D in Hashimoto's thyroiditis and its relationship with thyroid function and inflammatory status. Endocr J. 2018;65(10):1029-37. http://dx.doi.org/10.1507/endocrj.EJ18-0166. PMid:30058600.

16. Giovinazzo S, Vicchio TM, Certo R, Alibrandi A, Palmieri O, Campennì A, Cannavò S, Trimarchi F, Ruggeri RM. Vitamin D receptor gene polymorphisms/haplotypes and serum $25(\mathrm{OH}) \mathrm{D}(3)$ levels in Hashimoto's thyroiditis. Endocrine. 2017;55(2):599-606. http://dx.doi.org/10.1007/s12020-0160942-5. PMid:27043843.

17. Guleryuz B, Akin F, Ata MT, Dalyanoglu MM, Turgut S. Vitamin-D receptor (VDR) Gene polymorphisms (Taql, Fokl) in Turkish Patients with Hashimoto's Thyroiditis: relationship to the levels of Vit-D and cytokines. Endocr Metab Immune Disord Drug Targets. 2016;16(2):131-9. http://dx.doi.org/10.2174/1871530316666160728092613. PMid:27468766.

18. Hu S, Rayman MP. Multiple nutritional factors and the risk of Hashimoto's thyroiditis. Thyroid. 2017;27(5):597-610. http://dx.doi.org/10.1089/thy.2016.0635. PMid:28290237.

19. Kim D. Low vitamin D status is associated with hypothyroid Hashimoto's thyroiditis. Hormones. 2016;15(3):385-93. http://dx.doi.org/10.14310/horm.2002.1681. PMid:27394703.

20. Kim D. The role of Vitamin D in thyroid diseases. Int J Mol Sci. 2017;18(9):1949. http://dx.doi.org/10.3390/ijms18091949. PMid:28895880.

21. Mazokopakis EE, Papadomanolaki MG, Tsekouras KC, Evangelopoulos AD, Kotsiris DA, Tzortzinis AA. Is vitamin D related to pathogenesis and treatment of Hashimoto's thyroiditis? Hell J Nucl Med. 2015;18(3):222-7. PMid:26637501.

22. Aminorroaya A, Anaraki PV, Amini M, Momeni F, Feizi A, Iraj B, Tabatabaei A. Effect of Vitamin D deficiency treatment on thyroid function and autoimmunity markers in Hashimoto's thyroiditis: a double-blind randomized placebo-controlled clinical trial. J Res Med Sci. 2017;22(1):103. http://dx.doi.org/10.4103/jrms.JRMS_1048_16. PMid:29026419.

23. Štefanić M, Tokić S. Serum 25-hydoxyvitamin D concentrations in relation to Hashimoto's thyroiditis: a systematic review, meta-analysis and meta-regression of observational studies. Eur J Nutr. 2020;59(3):859-72. http://dx.doi.org/10.1007/s00394-019-01991-w. PMid:31089869.

24. Wang J, Lv S, Chen G, Gao C, He J, Zhong H, Xu Y. Meta-analysis of the association between vitamin $\mathrm{D}$ and autoimmune thyroid disease. Nutrients. 2015;7(4):2485-98. http://dx.doi.org/10.3390/nu7042485. PMid:25854833.

25. Higgins J, Green S. Cochrane handbook for systematic reviews of interventions. Hoboken: Wiley; 2021.

26. Page MJ, et al. PRISMA 2020 explanation and elaboration: updated guidance and exemplars for reporting systematic reviews. BMJ. 2021;372:n160. http://dx.doi.org/10.1136/bmj.n160. PMid:33781993. 
27. Atkins D, et al. Grading quality of evidence and strength of recommendations. BMJ. 2004;328(7454):1490. http://dx.doi.org/10.1136/bmj.328.7454.1490. PMid:15205295.

28. Aminorroaya A, Anaraki PV, Amini M, Feizi A, Iraj B, Tabatabaei A. Effects of Vitamin D deficiency treatment on metabolic markers in Hashimoto thyroiditis patients. J Res Med Sci. 2017;22(1):5. http://dx.doi.org/10.4103/1735-1995.199090. PMid:28400827.

29. Mukhopadhyay S, Chaudhary S, Dutta D, Kumar M, Saha S, Mondal SA, Kumar A. Vitamin D supplementation reduces thyroid peroxidase antibody levels in patients with autoimmune thyroid disease: an open-labeled randomized controlled trial. Indian J Endocrinol Metab. 2016;20(3):391-8. http://dx.doi.org/10.4103/2230-8210.179997. PMid:27186560.

30. Knutsen KV, Madar AA, Brekke M, Meyer HE, Eggemoen ÅR, Mdala I, Lagerløv P. Effect of vitamin D on thyroid autoimmunity: a randomized, double-blind, controlled trial among ethnic minorities. J Endocr Soc. 2017;1(5):470-9. http://dx.doi.org/10.1210/js.2017-00037. PMid:29264502.

31. Krysiak R, Szkróbka W, Okopień B. The effect of vitamin D on thyroid autoimmunity in levothyroxine-treated women with Hashimoto's Thyroiditis and normal vitamin D Status. Exp Clin Endocrinol Diabetes. 2017;125(4):229-33. http://dx.doi.org/10.1055/s-0042-123038. PMid:28073128.

32. Krysiak R, Szkróbka W, Okopień B. The effect of vitamin D and selenomethionine on thyroid antibody titers, hypothalamic-pituitary-thyroid axis activity and thyroid function tests in men with Hashimoto's thyroiditis: A pilot study. Pharmacol Rep. 2019;71(2):243-7. http://dx.doi.org/10.1016/j.pharep.2018.10.012. PMid:30818086.

33. Dizdar OS, Simsek Y, Cakir I, Yetmis M, Baspinar O, Gokay F. Effects of vitamin D treatment on thyroid autoimmunity. J Res Med Sci. 2016;21(1):85. http://dx.doi.org/10.4103/1735-1995.192501. PMid:28163731.

34. Wang S, Wu Y, Zuo Z, Zhao Y, Wang K. The effect of vitamin D supplementation on thyroid autoantibody levels in the treatment of autoimmune thyroiditis: a systematic review and a metaanalysis. Endocrine. 2018;59(3):499-505. http://dx.doi.org/10.1007/s12020-018-1532-5. PMid:29388046.

\section{Authors' contributions}

1. JMMFS contributed to study concept, study design, data collection, data interpretation, and writing of the manuscript.2. EVA contributed to data collection, data interpretation, and writing of the manuscript.3. ECOM contributed to data collection, data interpretation, and writing of the manuscript.

4. CAO contributed to data collection, data interpretation, and writing of the manuscript.5. AFB contributed to study concept, study design, data analysis, data interpretation, and reviewing of the manuscript. 
Vitamin D in patients with Hashimoto's disease: a systematic review and meta-analysis

\section{SUPPLEMENTARY MATERIAL}

The complementary information is available at OSF platform (DOI 10.17605/OSF.IO/9TH2G). 